\title{
BASIC ASPECTS WHEN USING IONIC LIQUIDS AS A HYDRAULIC FLUID
}

\author{
Darko Lovrec ${ }^{1 *}$, Roland Kalb² ${ }^{2}$ Vito Tič ${ }^{1}$ \\ ${ }^{1}$ University of Maribor, Faculty of Mechanical Engineering, Smetanova 17, SI-2000 Maribor, Slovenia \\ ${ }^{2}$ Proionic GmbH, Parkring 18, A-8074 Grambach, Austria \\ * Corresponding author: Tel.: +3862220 7611; E-mail address: darko.lovrec@um.si
}

\begin{abstract}
Hydraulic development engineers and tribology specialist still exert substantial effort, time and resources into finding a hydraulic fluid that would be near an ideal fluid. In addition to its basic physicochemical properties, it must meet a number of other requirements related to its practical use within hydraulic system and the materials used therein. Ionic Liquids, as novel lubricants, offer the solution in this regard.

The paper gives an overview of the basic properties of selected and tested Ionic Liquids suitable for use as hydraulic fluids. The practically obtained data refer to the basic physico-chemical properties of Ionic Liquids and properties important for practical use within hydraulic system, e.g. compatibility with materials. The results are given in a comparison with common mineral oil based hydraulic oil.
\end{abstract}

Keywords: Hydraulic fluids, Ionic Liquids, Properties, Material compatibility, Evaluation

\section{INTRODUCTION}

The lubricant used as a hydraulic fluid must fulfil a number of requirements. It would have to be non-flammable, non-poisonous, corrosion resistant, would have excellent lubricating properties, temperature-independent physicochemical properties and appropriate viscosity, furthermore energy efficient, mechanically resistant, providing a long service life of components wherein it is used. Besides, it should be also compatible with materials used within hydraulic components etc.

Lubricants' manufacturers try to approach these requirements with special additives added to commonly used mineral based oil in order to improve certain property (e.g. lower temperature dependence of viscosity), which can lead to the deterioration of other properties (e.g. foaming tendency). In addition, such additivated mineral based hydraulic oil or synthetic hydraulic fluid is not necessarily environmentally friendly, absolutely bio-degradable and may have negative effects on the environment. A completely new alternative that to reduce the various shortcomings of mineral based oils successfully are Ionic Liquids - ILs, used as novel, high efficiency lubricants.
Ionic Liquids represent a new class of hightech liquid materials with extraordinary properties that can have nanostructured organisation. A number of research findings have opened up many new areas of application for the use of these liquids, including hydraulics. Based on their unconventional properties ILs allow fundamentally new approaches to technical challenges. They have the potential to open doors to radical innovations. [1]

\section{IONIC LIQUIDS SELECTION PROCESS}

Ionic Liquids, a combination of cations and anions, a new class of purely ionic, salt-like materials that are liquid at unusually low temperatures, have been recognized as very promising high-performance lubricants and have attracted considerable attention within the field of tribology.

A large number of studies have already been carried out in this area so far, but only few with ILs suitable for use within hydraulic systems. The choice of cation and anion in an IL, as well as the design of ion side chains, determine the fundamental properties of IL, which permits the creation of tailor-made lubricants and lubricant additives. [2] 
When specified cation is combined with specified anion a new IL is obtained. While the process is not done by trial and error but rather knowingly, these can be synthesized into a completely new material with entirely new properties. In our case, we are searching for "liquid salts", which would have the characteristics of a perfect hydraulic fluid. The number of possible combinations of anions and cations is extremely high $\left(1.10^{18}\right.$ combinations $)$ that is why we have the opportunity to adapt each IL for particular usage.

Despite the excellent individual physicochemical properties, it is very difficult to find an IL that would combine the majority of favourable physico-chemical properties and characteristics of the "green", high performance hydraulic fluid. For well-known and widely used hydraulic oils, numerous of testing procedures have been developed in order to test almost all of their properties, while as in case of ILs, the situation is completely different. One possibility is to use the same methods as for conventional hydraulic fluids, or another possibility is to use your own, non-standard ones.

When isolating ILs appropriate for use as a hydraulic fluid, the procedures are not as uniformly definite as with other lubricants since their unique properties demand the use of special laboratory equipment. The most of laboratory measurements can be carried out by a wide assortment of typical analytical methods, out of which many were also applicable for ILs, e.g. measurements of density, viscosity, VI-index, corrosion resistance, lubricating properties, flammability, foaming tendency etc. These tests can be carried out within general laboratory using the conventional measuring devices and standards:

- Flash/fire point; ASTM D92/ASTM D93,

- Determination of density; ISO 12185,

- Kinematic viscosity; ASTM D445,

- Viscosity index; ASTM D2270,

- Corrosion in humid chamber; DIN EN ISO 6270-2,

- Corrosiveness to copper; ASTM D130,

- Demulsifying properties; ASTM D1401,

- Foaming of lubricating oils; ASTM D892,

- Welding point and wear diameter; IP 23985 ,

- Pour-point; ASTM D 97...

Measurement procedures, sample amounts and the equipment used, mainly relate to the conventional lubricants in accordance with the relevant standard. Tests of ILs properties based on procedures intended mainly for mineral based oils can serve us as a starting-point.

In addition to the mentioned standard tests, several specific, targeted measurements of physico-chemical properties were also used for testing the ILs, as well as for comparing the fluids. Some of these tests, e.g. measurement of breakdown voltage, filterability, Stribeck's curve, contact angle, or to check a compatibility with materials used within hydraulic system e.g. compatibility with reservoir paint coats, compatibility with different sealing material, measurement of compressibility and sound propagation... These tests need to be carried out with special measurement equipment, in specialised laboratories and/or under specific conditions, requirements or procedures. Some of these methods are adapted for testing Ionic Liquids and are not standardized.

\section{BASIC PROPERTIES TESTS}

Corrosion resistance, good lubricating properties, appropriate fluid density and suitable viscosity in the range of operating parameters, are undoubtedly the remarkably important fluid parameters that ensure long-lasting, energyefficient and cost-effective operation of the hydraulic system.

\subsection{Corrosion protection}

Good corrosion protection is a very important feature of a hydraulic fluid. Due to the fact that the Ionic Liquids are actually salts, it can be expected that the corrosion protection would be one of the parameters that is most difficult to achieve in comparison to conventional hydraulic fluids, particularly, the mineral-based oils. That was confirmed by laboratory tests, especially by the very harsh corrosion test in a humid chamber, where most of tested ILs resulted worse than the mineral hydraulic oil.

Resistance to corrosion was tested in three different ways:

- Corrosion test in humid chamber according to DIN 51386-1 and DIN EN ISO 6270-2 was conducted at constant conditions [3]. The chamber was closed throughout the test (with 
temperature of $40^{\circ} \mathrm{C}$ and relative humidity of $100 \%$ ), whereby resistance to corrosion is express in cycles $(1$ cycle $=24 \mathrm{~h})$.

- Standard test method for corrosiveness to copper according ASTM D 130-04.

- Corrosion in open air (practical method, in accordance with the real atmosphere/operating conditions).

Figure 1 shows the first signs of corrosion in a humid chamber for some tested ILs compared to mineral hydraulic oil HLP VG46. Relevant values in time are given in Table 1. It is evident that corrosion protection in most cases has not reached 1 cycle. In that case, the time in minutes or hours up to the occurrence of the first signs of corrosion is added in parentheses. According to this test the corrosion protection of tested ILs is worse in comparison to HLP mineral oil.

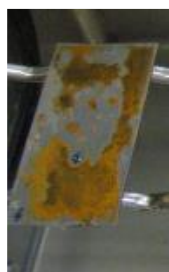

Without

protection

Figure 1:
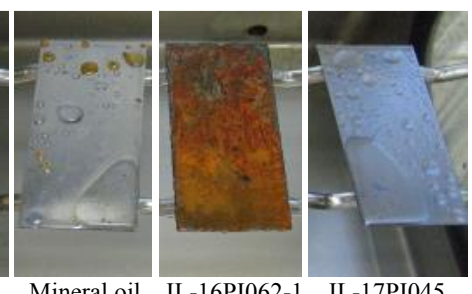

$$
\begin{aligned}
& \text { Mineral oil } \\
& \text { HLP VG } 46
\end{aligned}
$$

IL-16PI062-1 IL-17PI045

Figure 1: Test plates coated with different lubricants in humid chamber after $24 \mathrm{~h}$

In other cases the corrosion protection is comparable to that of the mineral-based hydraulic oil or even much better, as it can be seen on the last three samples in the Table 1 and respectively from Figure 1 (IL-17PI045).

Due to the presence of copper-based non-ferrous metals in hydraulic components, it is also necessary to perform a corrosion test of these materials. The corrosiveness to copper was carried out in accordance to ASTM D 130 Standard. Tests have shown that corrosiveness to copper is much lower than that of steel and does not represent any problems. [4]

Also a practical, non-standardised corrosion resistance test, where ILs-coated test plates were exposed to ambient air of average humidity, showed similar interdependencies. Unlike the very harsh test in a humid chamber, the times elapsed when the first signs of corrosion appeared were much longer: mineral oil after 60 days, EMIM-EtSO 4 after 2 to 3 days, while as in case of IL-17PI045 the corrosion has not appeared even after 3 months.
More information on corrosion tests, test procedures and conditions and more detailed results are available in the literature, e.g. [4].

When performing durability ILs testing under real operating conditions (changing operating pressure profile 10-210-10 bar, tank contact with ambient air, operating temperature $50^{\circ} \mathrm{C}$, load cycle time $2 \mathrm{~s}$, test duration 1 million cycles) after system disassembling and inspection of the vital hydraulic components (pump, tubes, proportional valve, cooler, sensors, tank, filter housing...) no signs of corrosion were observed.

\subsection{Lubrication properties and wear}

Lubrication properties were first examined using the 4-ball standard test method for lubricants; IP 239/85. With this method we have determined the welding-load and the wear-diameter and was used for the first evaluation of the lubricating properties of ILs. The friction conditions were investigated subsequently on the basis of the obtained results.

The lubricating properties of ILs, which have passed the corrosion test, are in general considerably better than those of conventional mineral based hydraulic oils or other liquid lubricants. Figure 2 shows the comparison between the welding-loads and wear-diameters' values for different samples of ILs compared to the mineral hydraulic oil HLP 46.

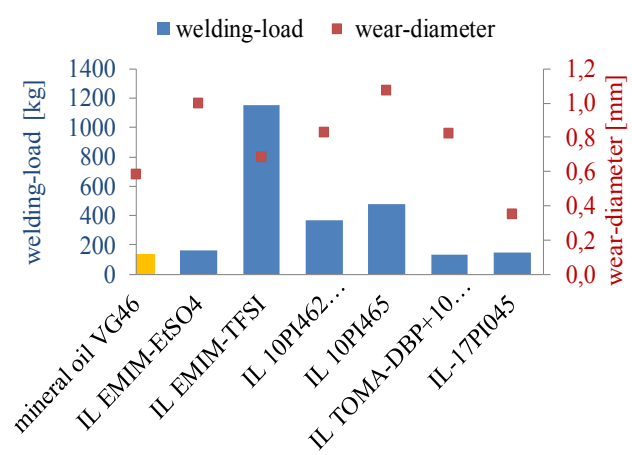

Figure 2: Lubrication properties of tested ILs in comparison with mineral oil

The lubricating properties of some ILs are considerably better than those of HLP VG46 mineral oil. Some samples have an exceptionally high welding-load, for example EMIM-TFSI had as much as $1150 \mathrm{~kg}$, which pointed out exceptional properties at extreme pressures but, 
interestingly, the wear-diameter was larger than that of the mineral oil, implying that the anti-wear properties were worse. Because the focus in on better wear properties this IL would be potentially more suitable for use in gearings, maybe even as metalworking fluid during metal machining. In regard to other ILs with high welding-loads values the limitation was, in particular, worse corrosive protection in the presence of moisture or in proper viscosity for the use in hydraulic systems.

The next approach to check the quality of lubrication is to perform Stribeck's test, representing the friction coefficient depending on the Stribeck's parameters, including viscosity, relative surface velocity and load. The measurements of Stribeck's curve for HLP hydraulic oil and some ILs were carried out using a MTM device for measuring friction and lubricating film thickness with ball-disc configurations.

The measured Stribeck's curves for VG46 mineral oil and two ILs at the ambient temperature $T_{\mathrm{o}}$ and $60{ }^{\circ} \mathrm{C}$ are shown in Figure 3 .

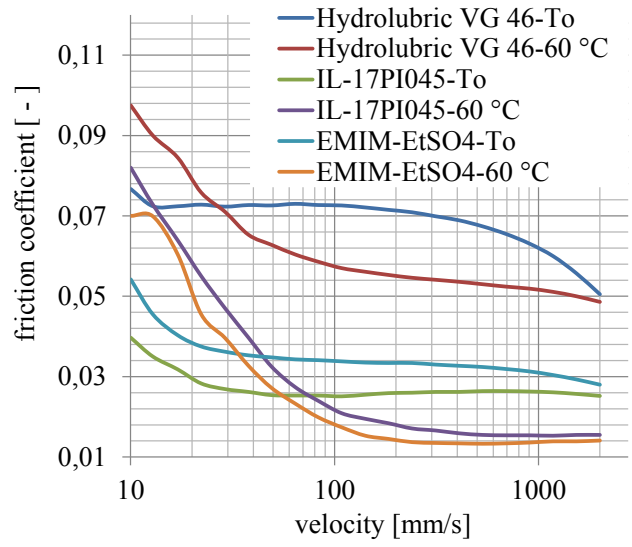

Figure 3: Stribeck's curves of two tested ILs vs. hydraulic mineral oil

It can be seen that the friction coefficient of the mineral oil within the entire range is considerably higher than that of both tested ILs. The two ILs have a very similar friction coefficient within the entire range, the IL-17PI045 having a slightly lower friction coefficient at room temperature, and the EMIM-EtSO ${ }_{4}$ at $60{ }^{\circ} \mathrm{C}$. All three fluids showed much larger difference between the lowest and highest measured values at $60{ }^{\circ} \mathrm{C}$ than at room temperature. Furthermore, at higher temperature the friction coefficient was higher in the range of boundary and mixed lubrication, and lower in the range of elasto-hydrodynamic lubrication. That is probably caused by a smaller lubricating film thickness at higher temperatures, resulting in more direct contacts of the ball and disc surfaces within the range of the boundary and mixed lubrication. More details regarding the lubricating properties, measuring principles and devices used, are given in literature [5] and [6].

\subsection{Density, viscosity and VI-Index}

One of the most important physico-chemical properties of hydraulic fluids is its kinematic viscosity. Viscosity is an essential property of lubricating oil as it affects its capacity to form a lubricating film or to reduce friction and wear. That is a criterion for resistance to flowing of the fluid under active pressure, except the flow-type, defines the leakage loses and is highly temperature dependent.

Suitable viscosity, with a sufficiently high load capacity of the lubricating film and its low temperature independence, make it possible to ensure the energy-efficient operation of the hydraulic system over a wide operating temperature range.

In case of too high fluid viscosity at low temperature, cavitation, insufficient lubrication and low system dynamic can occur, leading not only to reduced hydraulic-mechanical efficiency, but also to component damage (e.g. at insufficient filling of the pump). Cavitation can also occur when the liquid in a pump turns to a vapour at very low pressures.

On the other hand, too low viscosity at elevated temperatures leads to excessive leakage and, consequently, poor volumetric efficiency, and to insufficient lubrication. Due to the interruption of the lubricant film, this leads to increased friction and wear, which are reflected again in increased leakage.

Apart from the above-mentioned risks in the operation of the device, both too low and too high viscosities are reflected in the volumetric and hydraulic-mechanical efficiency, and, consequently, the overall efficiency.

The resulting requirements must be fulfilled by the lubricant in general: The ability of a lubricant to maintain optimum viscosity under a wide temperature operating window can be achieved with a shear stable fluid, with temperature independent viscosity (with high 
viscosity index VI), and with the low friction coefficient at starting and operating temperatures.

Lubricants' manufacturers try to achieve these requirements with special additives that improve certain properties (e.g. lower temperature dependence of viscosity), but, on the other hand, other properties may degrade. In addition, such a fluid is not completely environmentally friendly. Ionic Liquids, as a completely new alternative, solve most of these problems successfully, and can be used as novel high efficiency lubricants.

Kinematic viscosity was measured by capillary viscometers and is given in $\left[\mathrm{mm}^{2} / \mathrm{s}\right]$. The measurement is simple, fast and precise, as well as performed at two standard temperatures of measuring, $40{ }^{\circ} \mathrm{C}$ and $100^{\circ} \mathrm{C}$. The two kinematic viscosity data at both temperatures are, at the same time, the basis for determining the viscosity index. For the kinematic viscosity measuring, a Cannon-Fenske viscometer with the necessary peripheral equipment (tempered bath, stopwatch) was used and the measurement was performed according the ASTM D445 Standard.

The viscosity index values of higher refined mineral based oils on the market are about 100, while the multi-grade and synthetic oils have a higher viscosity index VI i.e. around 150 and higher. A favourable effect of expanding the temperature operating range can be achieved with a lubricant of the same viscosity class VG along with a higher viscosity index. The Ionic Liquids' viscosity indexes are, in general, higher than those of mineral based oils, wherein the viscosity grade can be adjusted.

The viscosity of most ILs can be deliberately adjusted, which is a significant advantage of these liquids. Another advantage is their high viscosity index, which is commonly much higher than VI of general HLP mineral oils.

Less "preferred property" is the density of ILs suitable for use as a hydraulic fluid, since their densities are usually higher than densities of mineral based hydraulic oils. Density of the ILs range from $944 \mathrm{~kg} / \mathrm{m}^{3}$ up to $1200 \mathrm{~kg} / \mathrm{m}^{3}$ or even higher (measured at $20{ }^{\circ} \mathrm{C}$ ). This property is negatively reflected in pressure loss, flow rate...

Table 1: Comparison of basic physicochemical properties

\begin{tabular}{|c|c|c|c|c|c|}
\hline Property/Method & \begin{tabular}{|c|} 
Viscosity \\
$40^{\circ} \mathrm{C}$ \\
ASTM D 445 \\
{$\left[\mathrm{~mm}^{2} / \mathrm{s}\right]$}
\end{tabular} & \begin{tabular}{|c|} 
Viscosity \\
index \\
ASTM D 2270 \\
[/]
\end{tabular} & $\begin{array}{l}\text { Welding } \\
\text { point } \\
\text { IP 239-85 } \\
{[\mathrm{kg}]}\end{array}$ & $\begin{array}{c}\text { Wear diameter } \\
\text { IP 239-85 } \\
{[\mathrm{mm}]}\end{array}$ & $\begin{array}{c}\text { Corrosion, } \\
\text { humid } \\
\text { chamber } \\
\text { DIN EN ISO } \\
6270-2, \text { cycle }\end{array}$ \\
\hline \multicolumn{6}{|l|}{ Sample } \\
\hline Mineral based oil VG 46 & 47,07 & 119 & 140 & 0,58 & $0(3 \mathrm{~h})$ \\
\hline IL-1 EMIM-EtSO 4 & 39,44 & 168 & 180 & 1,00 & $0(15 \mathrm{~min})$ \\
\hline IL-2 EMIM-TFSI & 71,89 & 132 & 1120 & 0,65 & $0(1,5 \mathrm{~h})$ \\
\hline IL-3 10PI462 (EMIM-TFSI) & - & - & - & - & $0(30 \mathrm{~min})$ \\
\hline $\begin{array}{l}\text { IL-4 16PI028-5 (quaternary } \\
\text { ammonium dialkylphosphate) }\end{array}$ & - & - & - & - & 0 (30 min) \\
\hline $\begin{array}{l}\text { IL-5 10PI028-3 (quaternary } \\
\text { ammonium perfluorocarboxylate) }\end{array}$ & - & - & - & - & 0 (45 min) \\
\hline $\begin{array}{l}\text { IL-6 16PI062-2 (quaternary } \\
\text { ammonium dialkylphosphate) }\end{array}$ & 59,14 & l & 135 & 0,82 & $0(4 \mathrm{~h})$ \\
\hline $\begin{array}{l}\text { IL-7 16PI062-1 (quaternary } \\
\text { ammonium perfluorocarboxylate) }\end{array}$ & 61,46 & l & - & - & $0(5 \mathrm{~min})$ \\
\hline $\begin{array}{l}\text { IL-8 18PI094 (quaternary } \\
\text { ammonium perfluorocarboxylate } \\
+30 \% \text { EG) }\end{array}$ & 49,28 & 109 & 125 & 1,04 & 0 (15 min) \\
\hline $\begin{array}{l}\text { IL-9 17PI064 (quaternary } \\
\text { ammonium dialkylphosphate }+7 \% \\
\mathrm{H}_{2} \mathrm{O} \text { ) }\end{array}$ & 102,90 & 105 & 190 & 0,49 & 1 \\
\hline $\begin{array}{l}\text { IL-10 18PI163 (quaternary } \\
\text { ammonium dialkylphosphate } \\
+40 \% \mathrm{NMP} \text { ) }\end{array}$ & 47,36 & 155 & 160 & 0,38 & $0(3,5 \mathrm{~h})$ \\
\hline IL-11 17PI045 & 46,59 & 155 & 145 & 0,35 & $0-1(>7,5 \mathrm{~h})$ \\
\hline
\end{tabular}




\section{OTHER PROPERTIES TESTS}

In addition to the basic physico-chemical properties mentioned in Chapter 3, other properties, such as compressibility (stiffness), foaming tendency, electrical conductivity and filterability, are also important for Ionic Liquids to be used as a hydraulic fluid.

\subsection{Compressibility of Ionic Liquids}

Bulk modulus of the fluid is crucial for hydraulic systems, particularly for high-pressure hydraulics. It can seriously affect a hydraulic system's performance and its power level, pressure peaks, response time, pulsation and control stability. Water-based hydraulic fluids are considered to be less compressible than conventional mineral oils (low bulk modulus values for oils). Ionic liquids, however, are even less compressible compared to the water. This makes ILs extremely interesting for hydraulic applications.

The compressibility of fluids can be measured in two ways; through changes in pressure and the volume by a known initial volume of the fluid and through the speed of sound that spreads across the fluid. Both mentioned methods were used to determine the compressibility of Ionic Liquids.

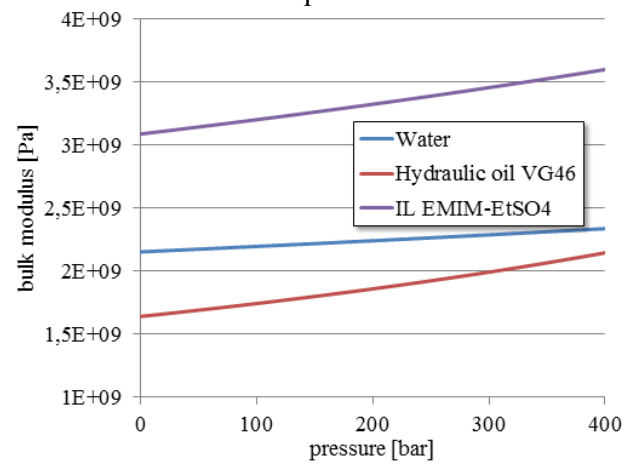

Figure 4: Measured bulk modulus versus pressure for all three considered fluids

More details on the specially designed compressibility testing device, measuring system and measuring procedure are available in the literature [7]. The measured compressibility (respectively bulk modulus) of one discussed IL (EMIM-EtSO4) in comparison to water and standard mineral based oil is shown in Figure 4.
The same applies to other types of Ionic Liquids. In regard to the dynamic behaviour of a hydraulic system with built-in IL as hydraulic fluid, special attention should be paid to the compressibility of the used IL.

Low compressibility of a hydraulic fluid leads to a high efficiency factor for a high-pressure machine. In general, all ILs are very incompressible liquids.

As shown in Figure 4, the bulk modulus value for EMIM-EtSO4 amounts approx. $3.2 \cdot 10^{9} \mathrm{~Pa}$, and is much higher than that of standard hydraulic mineral oil. This makes ILs extremely interesting for hydraulic applications; however, all the phenomena related to the compressibility of the medium must be taken into consideration: the magnitude of pressure shocks, the precision of positioning of the controlled actuators, the oscillations, the unsteady motion, or the pulsation of the hydraulic pumps [8].

\subsection{Foaming tendency}

The foaming tendency was analysed for Ionic Liquids with good corrosion protection and lubricating properties, but not in cases when it had been previously discovered that the IL is unsuitable for use as hydraulic fluid because of some other drawbacks. The standard foaming test of the promising samples of ILs e.g. IL-17PI045 were performed according to ASTM D 892 Standard in all 3 sequences. The results are generally positive, except for some samples of ILs e.g. 17PI064 (TOMA-DBP+7 $\left.\% \mathrm{H}_{2} \mathrm{O}\right)$ sample, where foaming in sequence I was extremely high. The results are indicated in table 2.

Table 2: Results of the foaming test - ILs vs. oil

\begin{tabular}{|c|c|c|c|c|}
\hline $\begin{array}{l}\text { Foaming test method } \\
\text { ASTM D } 892 \\
(\mathrm{ml} / \mathrm{ml})\end{array}$ & 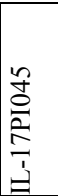 & 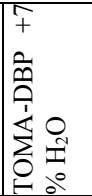 & 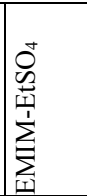 & 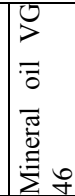 \\
\hline Sequence I. $\left(24^{\circ} \mathrm{C}\right)$ & $70 / 0$ & $600 / 20$ & $580 / 20$ & $0 / 0$ \\
\hline Sequence II. $\left(93,5^{\circ} \mathrm{C}\right)$ & $0 / 0$ & / & / & $30 / 0$ \\
\hline Sequence III. $\left(24^{\circ} \mathrm{C}\right)$ & $80 / 0$ & / & / & $0 / 0$ \\
\hline
\end{tabular}

When testing sample IL-17PI045 in sequences I and III, after completion of injection a small foam quantity was present. The foams were quickly disappearing and after 10 minutes they were no longer present. 
The sample IL-17PI045 e.g., had the more properties in the range of the mineral hydraulic oil, namely viscosity, viscosity index, corrosion properties, lubricating properties (higher welding point and smaller wear diameter than in the case of mineral oil; good foaming properties and compatibility with hydraulic system components. The greatest draw-backs included low boiling and flash points (because of the solvent content) and incompatibility with the usual tank paint coats, which means that during practical use the latter should not be painted.

The foaming problem occurs mainly in the consistent implementation of the standardized foaming test. Foaming was not a problem with the practical use of ionic liquids on a real hydraulic system, under realistic operating conditions. This point to a new aspect: the appropriateness of using the standard testing procedures, normally applicable to mineral oils, for completely new types of fluids, of a completely different composition. The same applies to the filterability test mentioned under point 4.4.

\subsection{Electric breakdown voltage}

In some cases, the hydraulic fluids are required to have similar properties as transformer oils, i.e. heat capacity, electric insulation and oxidation stability. High heat capacity and oxidation stability are two basic properties hydraulic oils must have, whilst good electric insulation is an additional requirement which must be met for specific systems, for example, when the electric motor is submerged in the hydraulic fluid.

Due to the (currently) higher cost of ILs, applications are targeted at small aggregates where this property may be important. According to the international standard IEC 60296, edition 4, 2012 "liquids for electro-technical applications - non-used mineral insulation oils for transformers and switching the breakdown voltage of the transformer oil denote their resistances to electric voltage in the electrical equipment. The breakdown voltage is measured according to standard IEC 60156.

Two ionic liquids IL-17PI045 and EMIMEtSO4 were tested and compared to the mineral hydraulic oil VG46. Measurements were performed by the use of the Megger OTS 60 PB apparatus in conformity with the standard. The results are indicated in table 3 .
Table 3: Breakdown voltages of ionic liquids and mineral hydraulic oil

\begin{tabular}{|c|c|c|}
\hline Fluid type: & 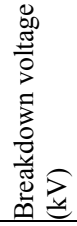 & 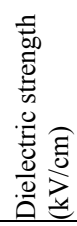 \\
\hline${\mathrm{EMIM}-\mathrm{EtSO}_{4}}_{4}$ & $<1,0$ & $<4$ \\
\hline IL-17PI045 & $<1,0$ & $<4$ \\
\hline Mineral oil VG46 & 60 & 240 \\
\hline
\end{tabular}

The breakdown voltages of mineral oils are very high and are quite comparable with best transformer oils (usually $40 \mathrm{kV}$ to $60 \mathrm{kV}$ ). On the other hand, the breakdown voltages of most ILs (among them e.g. EMIM-EtSO 4 ; and IL17PI045) are very low.

Therefore, they are not suitable for applications where the electric motor would be submerged in oil. That aspect must be considered when constructing hydraulic systems with small, compact units where, in some configurations, the electric motor without housing is directly submerged in the hydraulic fluid. For conventional hydraulic units design this property is not relevant.

\subsection{Filterability}

As the fluid in the hydraulic system acts as a lubricant reducing wear of hydraulic elements, elimination of solid particles in the circuit is very important. Especially, where clearances in the hydraulic system are small and a high degree of fluid cleanliness is required for trouble-free operation and reaching the expected useful life time of components. Since contaminants are removed by filters, the next relevant test is hydraulic fluid compatibility with filter cartridge material.

The ability of the hydraulic fluid to flow through fine filter elements without their clogging is called the filterability. The filterability of mineral oils is analysed according to ISO 13357 Standard [9], which imposes the use of a cellulose filter. In parallel with the mentioned filterability test with the cellulose filter material, additional material compatibility tests can be carried out.

As indicated in the ISO 13357 Standard, in addition to mineral oils the method can also be used also for other liquids. However, the latter are 
maybe not compatible with cellulose membrane filters, which, in our case, proved to be true. As both ILs (EMIM-EtSO 4; and IL-17PI045) deformed the cellulose filter membrane determination of filterability by this method was not possible. The filter element covered with IL17PI045 started to decompose immediately after the contact with liquid and dissolved rapidly. The sample of EMIM-EtSO ${ }_{4}$ deformed the filter element into a glassy circle. For more details see [4] and [10].

The above described problem is related to ISO 13357 test, which imposes the use of a cellulose filter. However, in practice there were no significant problems with IL filter compatibility observed, since generally other materials are used for filters.

Nevertheless, it would be necessary to supplement the suitability of this Standard for new types of hydraulic fluids - e.g. ILs.

\section{MATERIAL COMPATIBILITY}

Compatibility with materials commonly used in hydraulic components must be tested for each new hydraulic fluid. This is especially important in the case of Ionic Liquids. Mentioned filter material compatibility is only one aspect to the otherwise wide-ranging issue of material compatibility.

\subsection{Compatibility with paint coat}

Most hydraulic tanks are painted inside and outside using different types of paint coats. Therefore, it is very important that the IL used as hydraulic fluid is compatible with the used paint coat. As known, the compatibility the paint coats with mineral based hydraulic oils usually is not a problem.

Concerning protective coatings for hydraulic reservoirs, in particular the compatibility of the protective paint in regard to the type of hydraulic fluid, there is no specific standard which would be related to this issue in detail. There are more or less recommendations or recommended practices (RP), mostly linked to related areas, providing guidance on achieving effective corrosion control in storage tanks. They contain information about suitable lining materials, surface preparation, lining application, curing, and inspection of tank bottom linings for existing and new storage tanks, e.g. API RP652 Standard
- Linings of Aboveground Petroleum Storage Tank Bottoms. Thus, manufacturers of lubricants are using simple, practical experiments e.g. testing the continuous contact by immersing painted metal samples in the liquid under test, at constant room temperature: 20 to $25 \mathrm{oC}$.

The test of paint coat compatibility was performed with two selected ILs, IL-1 (EMIMEtSO4) and IL-11 (17PI045) - see Table 1. The metal plate samples were painted with two paints typically used for the tank interior and exterior. The interior is painted with epoxy primer coat, while the exterior is additionally coated with epoxy thick-layer finishing coat. Some metal plate samples were painted only with the interior paint while others were additionally painted with exterior finishing coat.

The test compromised about $40 \mathrm{ml}$ of each IL that were poured into glass cups; then single metal plate samples coated with either interior or exterior paint coat were introduced into them. At the beginning of the test the entire metal plates were wetted with the tested liquid; during testing the bottom part of the metal plate was permanently submerged into the liquid, while the top part was above the surface level as shown in Figure 5.

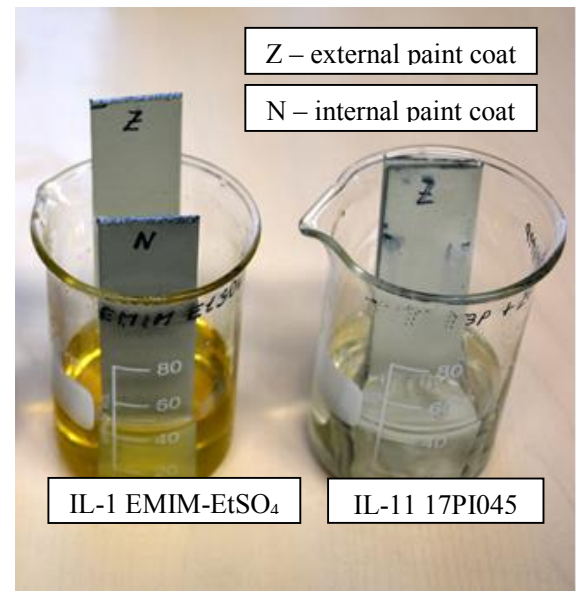

Figure 5: Test of compatibility with paint coats

Already after a few days of testing, it was clear that the IL-11 (17PI045, which in all previous tests proved to be an excellent substitute to mineral oil) was not compatible with internal, neither the external paint. The paint coat started to wrinkle and peeled off where the plate was permanently submerged into the test liquid. 


\subsection{Compatibility with seal materials}

The compatibility of an elastomer with hydraulic fluid is a critical factor in system performance. Although considerable effort has been invested in the attempt to empirically predict seal material compatibility, these efforts have not been successful to date.

One of the main reasons is the inability to accurately model the broad range of environmental conditions and chemical interactions encountered in an actual hydraulic system.

There are numerous elastomer seal materials. However, nitrile (NBR), fluorocarbon (FKM), ethylene propylene (EPR, EPDM), chloroprene $(\mathrm{CR})$, and urethane (AU, EU) are the most commonly used materials for industrial applications and they are still the subject of development.

A seal compatibility test procedure may be performed in accordance with ASTM D1414. Tests that should be performed on the O-rings refer to Hardness change, Volume swell, Shrinkage, as well as mechanical tests like Tensile strength change, Elongation change and Work function change. Detailed test procedure is described in the literature, e.g. [10], [11].

All materials, such as FPM, POM, HPU, NBR, HPU USI, EPDM, MVQ, PTFE I, and for the wear ring, e.g. SCB, PTFE, used for sealing are well compatible with the most commonly used mineral oils, so their material composition is focused to oils. In order to use well-known and established sealing materials with ILs, we need to test compatibility of each sealing material with each IL. Since this can be fairly extensive work, it is reasonable to test only ILs that have proven to be excellent in all the properties mentioned so far.

After conducting compatibility tests of most common sealing materials with certain types of ILs, we came to interesting findings. In some cases, no changes in dimensions, mass and volume of O-Ring were observed, as well as no change in the colour of the seal (e.g. POM, PTFE I with EMIM-EtSO4), or only minor changes occurred (NBR, EPDM, MVQ with EMIMEtSO4). On the other hand, some sealing materials in combination with certain ILs were completely decomposed in short test time.

In addition, the most suitable sealing material for a given IL (according to the standard test) turns out to be less suitable during the real operation. Conversely, the less appropriate one turns out to be a better solution.

The very briefly mentioned examples do not directly provide useful guidance on the selection of suitable sealing materials with a specific type of IL, but rather present how extremely complex it is to test otherwise well-known materials with new types of fluids.

Furthermore, test results obtained by standardised tests or recommendations may not be directly applicable to real operating systems under real operating conditions. This is especially important when we want to use an IL within a hydraulic system (that was designed for mineral oil) without major modifications.

\section{CONCLUSION AND OUTLOOK}

The presented results of the research work give the suggestions for the use of Ionic Liquids within hydraulic systems together with some limitations. The first ILs which would be tested were corrosive in the presence of moisture. Consequently, even greater attention must be paid to moisture prevention in the hydraulic system. Alternatively, stainless steel hydraulic components can be used, which, however, results in undesirable structural and price changes.

Some Ionic Liquids, such as e.g. IL-11 (17PI045), show the best proposition for use as a hydraulic fluid, since it has much better properties than mineral oil. But on the other hand is not compatible with conventional paint coats of hydraulic tanks. Therefore, the latter must not be painted, when that liquid is used. Another limitation in the use of this liquid is incompatibility with the cellulose filter elements. As a result, absorption filter elements, usually based on cellulose, could not be utilized, when this liquid is used in the hydraulic system.

At present, one of the greatest limitations for wider technical use of Ionic Liquids, also in hydraulic systems, is considerably higher price in comparison to conventional hydraulic mineral oil (due to the production of small quantities). The target areas of use of Ionic Liquids in hydraulic equipment are currently small-volume hydraulic systems, such as found in wind turbines, mobile hydraulic equipment etc. It follows that each type of IL needs to be tested individually for each important property, although some of its properties have proven to be excellent. 
Given information regarding different ILs physico-chemical properties, material compatibilities, testing procedures and Standards etc. can serve users as a guideline for the selection and use of Ionic Liquids as a hydraulic fluid. On the other hand, the information is also valuable to Ionic Liquids developers as first guidelines in which direction these fluids need to be developed in the future.

\section{REFERENCES}

[1] Kalb R (2015) Ionic liquids - A New Generation of High-Tech Engineering Liquids, International Conference Fluid Power 2015, Maribor, Slovenia, 49-77

[2] Feng Z, Yongmin L, Weimin L (2009) Ionic liquid lubricants: designed chemistry for engineering applications, Chemical Society Reviews, Vol. 9, No. 38, 2590-2599

[3] ISO 6270-2:2005 (2005) Paints and varnishes - Determination of resistance to humidity Part 2: Procedure for exposing test specimens in condensation-water atmospheres

[4] Kambič M, Kalb R, Tič V, Lovrec D (2018) Compatibility of ionic liquids with hydraulic system components, Advances in production engineering \& management, ISSN 1854-6250, doi: 10.14743/apem2018.4.306,Vol. 13, No. 4, 492-503

[5] Kambič M, Kalb R, Lovrec D (2015) Lubrication properties of ionic liquids suitable for use within hydraulic systems, International
Conference Fluid Power 2015, 79-93

[6] Lovrec D, Tič V (2019) Excellent lubricating properties of ionic liquid - myth or trut, $16^{\text {th }}$ International Conference on Tribology, ISSN 2620-2832, Vl. 1, No. 1, 555-562

[7] Kambič M, Kalb R, Tašner T, Lovrec D (2014) High bulk modulus of ionic liquid and effects on performance of hydraulic system, The Scientific World Journal, 1-10, doi: $10.1155 / 2014 / 504762$

[8] Tič V, Manhartsgruber B, Gubeljak N, Lovrec D (2018) Low compressibility of ionic liquids and its effects on pulsation within hydraulic system. Proceedings, fluid power networks, Vol. 1, $11^{\text {th }}$ International Fluid Power Conference, Aachen, Germany, 486-493

[9] ISO 13357-2:2005 Petroleum products Determination of the filterability of lubricating oils - Part 2: Procedure for dry oils

[10]Lovrec D (2017) Filterability of ionic liquid used as a hydraulic fluid. The $5^{\text {th }}$ Multidisciplinary Conference QUAESTI, Proceedings, ISSN 2453-7144, Vol. 5, Iss. 1, 160-164

[11] ASTM D 6546, Standard Test Methods for and Suggested Limits for Determining Compatibility of Elastomer Seals for Industrial Hydraulic Fluid Applications

[12] Kalb R, Lovrec D (2019) Seal material compatibility test procedure, International Conference Fluid Power 2019, $1^{\text {st }}$ ed. University of Maribor Press, 133-146 